The diet should be nourishing and stimulating; when he cannot take food in the ordinary manner it should be given as a rectal injection, two ounces at a time, or in the form of zyminised beef or milk suppositories; at the same time a removal to the coast will probably benefit him. Electricity or galvanism over the spinal column might serve to stimulate the nervous system and rouse him from his apathy. Where there is anæmia, whether malarial or not, the following is useful :- $\mathrm{K}$. Tinctura digitalis $3 \mathrm{ss}$, tinctura capsici $3 \mathrm{ss}$, liquor ferri perchlor. 3 ii., aqua chloroformi ad 5 viii. ; one ounce to be taken three times a day. It is probable, too, from my later researches on the subject, that tabloids of thyroid gland might be useful in stimulating the cerebral circulation. If Dr. Manson's theory ${ }^{3}$ is correct, then the treatment would be by compound sulphur tabloids, as in the treatment of filaria medinensis $;^{4}$ still continuing, however, the tonic treatment until success should crown our efforts or death render further attention unnecessary. Before closing, I may state that the treatment of this affection by the native doctors consists in excising the enlarged cervical glands, which apparently influences the disease but little.

St. Augustine's-road, N.W.

\section{Climital enters:}

\section{MEDICAL, SURGICAL, OBSTETRICAL, AND THERAPEUTICAL.}

\section{EXTRA-PERITONEAL VESICAL HERNIA.}

By W. Arbuthnot Lane, M.S. Lond., F.R.C.S. Exg. ASSISTANT SURGEON TO GUY'S HOSPITAL AND THE HOSPITAL FOR SICK CGILDREN, GREAT ORMOND STREET.

THE following case is of much interest in reference especially to the case recently communicated to the Royal Medical and Chirurgical Society by Dr. Krnst Michels, ${ }^{1}$ and particularly as he states that the condition is such a rare one, since only five cases have hitherto been published.

A Hindoo aged fifty-one years was admitted into Guy's Hospital on March 20th, 1894, suffering from a large inguinal hernia on the left side. It was partly reducible, and on examining it carefully it was obvious that the portion that was returnable into the abdomen was of the character of intestine, while the lumpy, bulky, hard mass that remained was probably fatty and adherent omentum. The patient was stout enough to make a more certain and minute examination of the structural details of the hernial sac and its contents impossible. The condition caused him consi erable discomfort, from which he was anxious to be relieved. Consequently on April 6th I exposed the upper part of the sac and adjacent surface of the abdominal wall and turned out the whole sac. I then found the following unusual conditions. The hernial sac was covered with large masses of fat, and outside the sac, and lying external to it and slightly below it was a long process as large as a good big thumb and of much the same shape. On squeezing it fluid could be forced into the abdomen, and on relaxing the pressure it quickly filled up with fluid. Its wall resembled in structure that of the normal bladder, of which it appeared to be a protrusion. It was incised at its summit, when the urine, which was known previously to be perfectly healthy, escaped. The finger was then passed into it, when it was found to fit it loosely. The orifice of communication with the bladder felt somewhat narrower than the lamen of the protrusion. The edges of the mucous membrane were inverted and brought together by sutures, and outside this another row was applied. The protrusion was freed from its somewhat intimate association with the hernial sac and was returned into the abdominal cavity. The sac and its lipomatous growths, together with the adherent fatty omentum in its interior, were removed, and the lumen of the inguinal canal and of its external ring was suitably diminished by means of sutures. Though I have found the bladder in the wall of, and forming a part of, a hernial sac on more than one occasion, and in young children have observed it to prolapse readily through the internal ring, I have never seen a protra sion of a permanent form, such as that $I$ here describe outside and practically having no connexion with the wall of the hernial sac. The question of the relative position of the bladder or an outgrowth of it to the hernial wall seems to have been somewhat confused in the reports of the discussion on Dr. Michels' communication.

St. Thomas's.street, S.E.

NOTE ON THE ACTION OF IODINE.

By Dawson TURNer, M.D. Edin., M.R.C.P. LoNGa, LECTURER ON PHYSICS AT SURGEONS' HALL, EDINBURGH.

The value of iodine as an absorbent has long been knowr. It is used to cause absorption of enlarged glands, thickenings due to chronic inflammation, and serous effusions, and this action is believed to be due to a stimulation of the lymphatic system. Perhaps the most remarkable results due to the action of a compound of iodine as an absorbent are those which were attained by Major Holmes or Captain Cunningham in the treatment of goitre in India. They recommended that the enlarged thyroid should be smeared over with the red iodide of mercury ointment, and that then the patient shoulc be made to sit with his neck exposed to the rays of the sun or of hot fire for many hours. The results were extraordinarp Sixty thousand natives were treated gratuitously in two years, and a cure was almost always effected. ${ }^{1}$ My object in this communication is to offer a suggestion from the point of view of the physicist as to the mode of action of the iodine in these cases. We use iodine in physical experiments to cut off the visible rays of the spectrum. A solution of iodine in bisulphide of carbon will quench the visible rays of the sun, but will transmit the invisible heat rays. The solution is, is fact, remarkably transparent to the heat rays : it is diather. matous. Professor Tyndall in 1868 was, I think, the firat to point this out. Now, the fact that Major Holmes found that the action of the red iodide of mercary was much intensified by exposing the patients to the direct rays of the sun has appeared to me to depend upon the physical action of the iodine that $I$ have mentioned. At any rate I offer this as a suggestion. Further, the fact that the red iodide is the most efficacious points in the same direction, because the red substance would also serve to transmit the heat rays only. The solar radiation would be filtered by the application, and the gland would be subjected to the fall blaze of the calorific rays without the vibra. tions of its molecules being altered by the visible rays. Pro. fessor Tyndall ${ }^{2}$ made some experiments with paper reddened by the red iodide and found that it was also highly trasss. parent to obscure radiation; it therefore falls into line witb simple iodine. If my suggestions as to the mode of action of iodine be correct, we do wrong in covering diseased parts to which iodine has been applied; we ought rather to expose them freely to the rays of the sun, or, failing that, to those of a good fire.

George-square, Edinburgh.

\section{CASE OF URTICARIA PRODUCED BY SANTONIN.}

By G. Stewart Abram, M.B. Cantab., M.R.C.S. EvG , L. R. C.P. LOND.

THE following case of urticaria produced by santonin, which has lately come under my notice, appears to $\mathrm{ms}$ to present interesting features:-

A. B-C, a child seven years of age, was brought to mo on April 21st, 1894, suffering from thread worms, which, her mother said, had been present for some three years. She had been under treatment once before for this cause, but had not taken santonin on that occasion. There was nothing remarkable in the child's appearance, except that she was rather pale and flabby and had a slight cough. I ordered her santonin powders (three grains), to be taken fasting on alternate mornings for three days, preceded on the previous night by castor oil and followed by a similar dose. She had a dose of castor oil on the night of April 21st and her first powder at $7 \mathrm{~A}$.M. on the $22 \mathrm{nd}$. On this occasion the only sign of any eruption was a red odematous patch the

Quain's Dictionary of Medicine.

2 Heat as a Mode of Motion, chapter xiii. 